\title{
Phylogenetics of Morus (Moraceae) Inferred from ITS and trnL-trnF Sequence Data
}

\author{
Madhav P. Nepal ${ }^{1,3}$ and Carolyn J. Ferguson ${ }^{2}$ \\ ${ }^{1}$ Department of Biology and Microbiology, South Dakota State University, Brookings, South Dakota 57007-1898 U. S. A. \\ ${ }^{2}$ Herbarium and Division of Biology, Kansas State University, Manhattan, Kansas 66506-4901 U. S. A. \\ ${ }^{3}$ Author for correspondence (Madhav.Nepal@sdstate.edu) \\ Communicating Editor: Andrew Hipp
}

\begin{abstract}
Morus (Tribe Moreae, Moraceae) consists of ca. 13 species of trees distributed in Asia, Africa, Europe, and North, Central, and South America. The broad geographical distribution of the genus, overlapping ranges of many taxa, and documented hybridization between some species present interesting questions of taxonomy, phylogeny, and biogeography. Phylogenetic data for Morus also contribute to higher level taxonomic work in the family. We used sequence data from ITS of the nrDNA and the chloroplast trnL-trnF intergenic spacer to study phylogenetic relationships of Morus. Phylogenies based on separate data sets were not statistically incongruent, and the combined tree reveals that Morus, as currently circumscribed, is non-monophyletic. Subgenus Morus (sensu Leroy) is resolved as a clade and consists of two wellsupported clades: one of Asian taxa and one of North American taxa. Sampled members of the genus Trophis (two, including the type) form a clade sister to subgenus Morus. Morus mesozygia (Africa; subgenus Afromorus) and M. insignis (Neotropics; subgenus Gomphomorus), which have not been included to date in other phylogenetic studies of the family, are placed outside the subgenus Morus-Trophis clade. This work is an important step in elucidating relationships of Morus and along with other recent phylogenetic studies in Moraceae, underscores the need for further work within Tribe Moreae to clarify natural generic relationships.
\end{abstract}

Keywords-ITS, Moraceae, Moreae, Morus, phylogeny, trnL-trnF.

Morus L. (Moraceae) comprises 10-13 species (Berg 2001, 2005a) distributed in Asia, Africa, Europe, and North, Central, and South America. Morus species are economically important to the silk industry, as they are host plants for the silkworm (Bombyx mori L.) larvae (Watanabe 1958). Additionally, species have been cultivated in many parts of the world for their edible fruits and as ornamental trees. Morus is the type genus of the cosmopolitan family Moraceae, which includes 37 genera, some of which have been subjects of recent phylogenetic work (e.g. Artocarpus, Zerega et al. 2010; Ficus, Rønsted et al. 2008). Tribal classification within Moraceae has received much attention in recent years, with both taxonomic and phylogenetic study spurring realignments (Berg 2001, 2005a; Datwyler and Weiblen 2004; Clement and Weiblen 2009). Closest relatives to Morus include Bagassa Aubl., Milicia Sim, Sorocea A. St.-Hil., Streblus Lour. (in part), and Trophis P. Br. (in part), tribe Moreae of Clement and Weiblen (2009). However, Moreae remains paraphyletic pending further study and recircumscription of Streblus and Trophis, each of which include species more closely related to tribe Dorstenieae Gaudich. (based on ndhF and 26S data; Datwyler and Weiblen 2004; Zerega et al. 2005; see also Clement and Weiblen 2009); and Weiblen and colleagues call for further work on these genera (Datwyler and Weiblen 2004; Clement and Weiblen 2009). Tribe Moreae exhibits pleisiomorphic characters including a simple inflorescence, tetramerous flowers and usually inflexed ("urticaceous") stamens (see Sytsma et al. 2002; however the recent transfer of genera in and out of Moreae makes the tribe more heterogeneous with respect to this pleisiomorphy); sampling of member genera has been limited in phylogenetic studies to date and is important to further our understanding of the tribe and systematics of Moraceae as a whole.

Morus is defined by a suite of characters including cauducous terminal buds, catkins, staminate flowers with imbricate perianth, inflexed stamens, pistillate flowers with valvate perianth and \pm equally branched stigmas, fleshy perianth in the fruit, and a berry-like syncarp (see Berg 2001; Nepal 2008). Species are considered wind pollinated (based on morphology; Berg 2001) and fruits are often dispersed by birds (Stapanian 1982). Characters including morphology of the leaf, winter bud, bark, pistil, and syncarp have generally been employed in species recognition. The base chromosome number is $x=14$ (Janaki-Ammal 1948; Chen et al. 1993; Azizan and Sonboli 2001; Awasthi et al. 2004), and polyploids with counts as high as $2 n=308$ (probably in cultivars; e.g. Azizan and Sonboli 2001) have been reported. The genus is interesting for systematic study because of its wide geographical distribution, morphological plasticity (Gray and Gray 1987), hybridization (Burgess et al. 2005), long history of domestication, and introduction and naturalization of species in areas remote from their native ranges (Tojyo 1985).

There has long been great taxonomic interest in Morus, at least in part due to its economic importance. Linnaeus (1753) established the genus and described seven species: M. alba L., M. indica L., M. nigra L., M. papyrifera L., M. rubra L., M. tartarica L. and M. tinctoria L. Of these, M. papyrifera and $M$. tinctoria were later moved to the genera Broussonetia L'Hér. ex Vent. (B. papyrifera (L.) L'Hér. ex Vent.) and Maclura Nutt. (M. tinctoria (L.) D. Don ex Steud.), respectively. Bureau (1873) recognized five species, and also described 21 varieties and 13 subvarieties (with taxonomic emphasis on syncarp shape and style length within M. alba). Greene (1910) treated Morus in the southwestern U. S. A., dividing M. microphylla into 13 species. Koidzumi (1917), who presented the most recent genus-wide treatment, recognized 24 species under two major sections: Section Macromorus Koidz. (= Sect. Morus; species with short styles, $<0.5 \mathrm{~mm}$ ) and Section Dolichostylae Koidz. (species with long styles, $>1 \mathrm{~mm}$ in length). Thus, in his classification, Koidzumi promoted some of Bureau's varieties to species (and some of Bureau's conspecific varieties became species classified into separate sections within the genus). Leroy (1949), in his article on sericulture in the tropics, provided a classification of Morus dividing the genus into three subgenera, each with geographic integrity: Eumorus J. F. Leroy (= Subg. Morus; Asian and North American Morus, including one species also ranging into Central America), Gomphomorus J. F. Leroy (M. insignis from Central and South America; and M. trianae J. F. Leroy, now considered a synonym of the former [Berg 2001]), and the monotypic Afromorus A. Chev. (M. lactea (Sim) Midlbr., now considered a synonym 
of M. mesozygia Stapf., from Africa). Hotta (1954) studied variation in shape and position of leaf cystolith cells in M. alba, M. australis, and M. mongolica. Katsumata (1971) studied size and shape of leaf ideoblasts and used these data to classify several races of $M$. alba and $M$. australis. Other important taxonomic studies on Morus include description of new species from China (Chang 1984; Wu and Chang 1989; Cao 1991), lectotypification of M. alba (Rao and Jarvis 1986), an overview of Morus distribution (Sanjappa 1989), and revision of Morus in the Flora of China (Zhekun and Gilbert 2003). Zhekun and Gilbert (2003) recognized 12 species in China alone, although workers outside of China have generally not concurred with recognition of such great diversity at the species rank.

Taxonomic and floristic work on Moraceae worldwide has been conducted by Berg (e.g. Berg 2001, 2005a, 2005b). He has most recently estimated the number of species in Morus at $10-13$ or 12 (2001, 2005); however, he has not enumerated those species, and has noted the need for taxonomic revision of the genus. Based on synthesis of taxonomic literature on Morus and examination of herbarium specimens (> 1,500 specimens from U. S. A. herbaria; Nepal 2008), 13 distinctive Morus species can be recognized: eight species native to Asia (see Appendix 1 for authorities; M. alba, M. australis, $M$. cathayana, M. macroura, M. mongolica, M. nigra, M. notabilis, and M. serrata), four New World species (M. celtidifolia, M. insignis, M. microphylla, and M. rubra), and one species occurring in Africa (M. mesozygia). Three Asian species (M. australis, M. notabilis, and M. mongolica) have long styles (sensu Koidzumi; range 1-11 $\mathrm{mm}$ ), while the remaining species have short styles (range 0-0.5 mm). Species with the longest catkins $(6-16 \mathrm{~cm}$, versus $0.5-2 \mathrm{~cm}$ in other species) are M. macroura (occurring in tropical cloud forests in East Asia) and M. insignis (in tropical cloud forests in Central and South America). The African M. mezozygia differs notably from all other species in its distinctly trinerved leaf lamina with scalariform secondary veins from the midrib, and a peduncle longer than the infructescence. Given diversity of the genus Morus, development of a phylogenetic framework in the context of family relationships will be valuable (family-wide phylogenetic studies have included at most two species of Morus; Datwyler and Weiblen 2004; Zerega et al. 2005; Clement and Weiblen 2009).

Several studies have used genetic approaches to study diversity within Morus. Zhao et al. (2005) sequenced the ITS region of nrDNA and the chloroplast $\operatorname{trn} L$ intron to investigate genetic distances among some Asian taxa (including M. alba, M. australis, M. macroura, and M. mongolica). Molecular markers widely used in population genetic studies including randomly amplified polymorphic DNA (RAPDs) and inter simple sequence repeats (ISSRs) have also been employed to study patterns of genetic relationships among species of Asian Morus (e.g. Sharma et al. 2000; Bhattacharya and Ranade 2001; Awasthi et al. 2004; Vijayan et al. 2004; Vijayan et al. 2006; Zhao et al. 2007). More than thirteen microsatellite markers are available for Asian Morus species (see Aggarwal et al. 2004; Tani et al. 2005). Most of these studies focused primarily on the cultivated species in Asia with an aim toward improving cultivars for the silkworm industry.

The objective of the present study was to develop phylogenies for Morus to advance taxonomic study of the genus and to place findings within the context of taxonomic and phylogenetic work on the family. In this study we present phylogenies for the genus Morus based on sequence data from ITS and the chloroplast trnL-trnF intergenic spacer region, and discuss the implications.

\section{Materials AND Methods}

Taxon Sampling-Thirteen species of Morus (Appendix 1) as well as one species of Sorocea and two species Trophis (Appendix 2) were sequenced and used as ingroup taxa, and Artocarpus heterophyllus, Tribe Artocarpeae R. Br., was selected as an outgroup (see Clement and Weiblen 2009; Zerega et al. 2010). Additional available sequences of Tribe Moreae sensu Clement and Weiblen (2009) were included as part of the ingroup for phylogenetic analyses, as possible: Bagassa (one species; ITS and trnL$\operatorname{trnF}$ ), Milicia (one; ITS); Sorocea (two additional species; ITS and trnL$\operatorname{trnF}$ ); and Streblus (five; four ITS and three trnL-trnF; Appendix 2).

DNA Isolation and PCR Amplification-Total DNA was extracted from leaf material (dried in silica gel or from herbarium specimens) following the CTAB protocol of Loockerman and Jansen (1996; modified from that of Doyle and Doyle [1987]), or using a DNeasy plant mini kit (Qiagen Corp., Valencia, California). The ITS region (ITS1, the 5.8S coding region and ITS2) and the chloroplast intergenic spacer region $\operatorname{trnL}$-trnF (partial $\operatorname{trn} L_{\mathrm{UAA}}$ intron, $\operatorname{trn} L$ gene, intergenic spacer between $\operatorname{trn} \mathrm{L}_{\mathrm{UAA}}$ and $\operatorname{trnF}$, and partial $\operatorname{trnF}$ ) were amplified with the primers ITS4 (White et al. 1990) and modified ITS5 (Downie and Katz-Downie 1996), and the primers ' $c$ ' and ' $f$ ' (Taberlet et al. 1991), respectively. The PCR was conducted in a reaction mixture of $50 \mu \mathrm{l}$ containing $\sim 25 \mathrm{ng}$ genomic DNA, $2 \mathrm{mM}$ of PCR buffer, $0.4 \mu \mathrm{M}$ of primer, $0.2 \mathrm{mM}$ of each dNTP and 1 unit of Taq polymerase with $1.25 \mathrm{mM}$ and $2.5 \mathrm{mM}$ of $\mathrm{MgCl}_{2}$ for ITS and trnL-trnF, respectively. "Hot start" PCR conditions were: 1) for ITS amplification: initial denaturation at $94^{\circ} \mathrm{C}$ for 5 minutes followed by 1 minute at $72^{\circ} \mathrm{C}$ during which time Taq polymerase was added; and 35 cycles of 1 minute denaturation at $94^{\circ} \mathrm{C}, 1$ minute annealing at $50^{\circ} \mathrm{C}$, and 2 minutes elongation at $72^{\circ} \mathrm{C}$; and a final elongation of 5 minutes at $72^{\circ} \mathrm{C}$; and 2) for trnL-trnF: initial denaturation at $94^{\circ} \mathrm{C}$ for 5 minutes followed by 1 minute at $72^{\circ} \mathrm{C}$ during which time Taq polymerase was added, and 28 cycles of 1 minute denaturation at $94^{\circ} \mathrm{C}, 1$ minute annealing at $55^{\circ} \mathrm{C}$, and 2 minutes elongation at $72^{\circ} \mathrm{C}$; and a final elongation of 10 minutes at $72^{\circ} \mathrm{C}$. The PCR products were purified using a QIAquick purification kit (Qiagen Corp.).

Sequencing and Alignment-Sequencing reactions in both directions were performed using Big Dye V3.1 kit (Applied Biosystems Inc., Framingham, Massachusetts; following the manufacturer's instructions, except that quarter reactions were used). The sequencing reaction conditions were as follows: $96^{\circ} \mathrm{C}$ for 2 minutes; followed by 25 cycles of $96^{\circ} \mathrm{C}$ for $15 \mathrm{sec}, 50^{\circ} \mathrm{C}$ for $1 \mathrm{sec}$, and $60^{\circ} \mathrm{C}$ for 4 minutes; and subsequent storage at $4^{\circ} \mathrm{C}$. Sequenced reactions were purified through Sephadex (Sigma, St. Louis, Missouri) columns, dried using a vacuum-centrifuge, and sent to the DNA Sequencing and Synthesis Facility at Iowa State University where gels were run using an ABI 3700 automated sequencer. Resulting sequences were aligned and edited using Sequencher 4.5 (Gene Codes Corp., Ann Arbor, Michigan), and the data matrices constructed (with inclusion of additional sequences from GenBank) and aligned manually using Se-Al (Rambaut 2002).

Phylogenetic Analyses-Data sets were analyzed using maximum parsimony (MP), maximum likelihood (ML), and Bayesian inference (BI) methods. The MP and ML analyses were performed in PAUP* $4.0 \mathrm{~b} 10$ (Swofford 2002) using branch and bound and heuristic searches, respectively. All characters were treated as equally weighted and unordered. Parsimony analyses were performed treating gaps as both missing data and as a fifth character state. Modeltest (version 3.06; Posada and Crandall 1998; Posada and Buckley 2004) was used to determine the substitution model that best fit the Morus sequence data. The parameters of the best model under the Akaike Information Criterion (AIC) were used in ML and BI analyses. The PAUP "command block" resulting from Modeltest was appended to each data matrix for specifying the evolutionary model during ML analysis. Bootstrapping (Felsenstein 1985) was performed to assess support for branches (20,000 full heuristic replicates for MP and 1,000 replicates for ML analyses).

The BI analyses were performed in MrBayes (ver. 3.1.2; Huelsenbeck and Ronquist 2001). Model parameters for the substitution model K81uf + $G$ were specified and each analysis was conducted with two independent runs with four (three heated and one cold) Markov Chain Monte Carlo (MCMC) chains for two million generations starting from a random tree. The number of generations required to bring the standard deviation of split frequencies between runs below 0.01 was identified as the minimum number of generations required for the analysis. Trees were saved every 
100 generations for 2,000,000 generations, producing 20,000 trees. Majority rule consensus trees and posterior probabilities (PP) for each node were calculated from the trees after the first $25 \%$ of trees $(500,000$ generations) was discarded as burn-in.

Incongruence Testing and Combined Data Analysis-A combined data matrix of ITS and trnL-trnF was constructed (with 20 taxa), and the incongruence length difference (ILD) test (Farris et al. 1994) was performed to assess congruence between these two data sets. The ILD test was conducted using the partition homogeneity test as implemented in PAUP*, using a heuristic search with 1,000 replicates. The ILD test was non-significant ( $p$ value $=1$ ), indicating the data could be appropriately combined. Phylogenetic analyses of the combined data set were performed as described above (and, as the same evolutionary model was used for both ITS and trnL-trnF, the combined data set was not partitioned).

\section{RESULTS}

Data Matrices-Sequences of the ITS region in Morus ranged from 611-635 base pairs (bp), and from 936-944 bp for trnL-trnF. GenBank accession numbers are provided in Appendices 1 and 2, and data matrices are available on TreeBASE (study number 11391). There were $666 \mathrm{bp}$ and 25 taxa in the complete, aligned ITS data matrix (including 13 indels one bp in length, and eight indels > one bp), $981 \mathrm{bp}$ and 21 taxa in the trnL-trnF data matrix (including seven indels of one bp and six indels > one bp), and 1,640 bp and 20 taxa in the combined data matrix. A $17 \mathrm{bp}$ region of ITS1 was excluded from analysis due to ambiguous alignment. Analysis of the ITS data revealed that ITS1 (not counting the excluded characters) and ITS2 are equally variable, but ITS1 has more parsimony informative characters than ITS2 (Table 1). The 5.8S region within most of Morus is not variable, but there are eight variable sites in the $5.8 \mathrm{~S}$ region for the ingroup taxa as a whole, two of which are parsimony informative. Analysis of the trnL-trnF data matrix revealed that the $t r n \mathrm{~L}$ intron has fewer variable sites than the $t r n L-t r n F$ spacer, but the former has slightly more informative sites than the latter, which is in contrast to findings for these regions in many taxa for which comparisons have been made (see Shaw et al. 2005).

Phylogentic Analyses-Statistics for the MP analyses are presented in Table 1. MP analysis of the ITS data set resulted in 77 most parsimonious trees when gaps were treated as missing, and eight most parsimonious trees with gaps coded as a fifth character state. The tree topology in the latter case did not change except in the additional resolution of a clade containing $M$. australis and $M$. notabilis. Overall bootstrap (BS) support was also higher with gaps coded as a fifth character state. The strict consensus tree is presented in Fig. 1. The MP analysis of the trnL-trnF data set yielded 87 most parsimonious trees when gaps were treated as missing, and 18 most parsimonious trees with gaps treated as a fifth character state (Fig. 1). The ML and BI analyses of each data set with the common substitution model $(\mathrm{K} 81 \mathrm{uf}+\mathrm{G})$ yielded similar results to the MP analyses; BI posterior probabilities are reported in Fig. 1. The parameter values for the substitution model were: base frequencies for $A, C, T$ and $G$ as $0.35,0.17,0.16$ and 0.30 , respectively; rate matrix $\mathrm{R}[\mathrm{a}], \mathrm{R}[\mathrm{b}]$, $\mathrm{R}[\mathrm{c}], \mathrm{R}[\mathrm{d}], \mathrm{R}[\mathrm{e}]$ and $\mathrm{R}[\mathrm{f}]$ as $1.00,2.47,0.25,0.25,2.47$ and 1.00, respectively; and gamma shape of 0.1005 . The $-\ln \mathrm{L}, \mathrm{K}$, and $\triangle \mathrm{AIC}$ values for the K81uf $+\mathrm{G}$ model were 1,828.86, 53 and 2.4326, respectively.

Phylogenetic Relationships-Phylogenies based on ITS and trnL-trnF were similar in topology (see Fig. 1), and trees resulting from analyses of the combined data (Figs. 2-3) reveal that:

1) Most Morus species form a well-supported clade that corresponds to subgenus Morus sensu Leroy (100\% MP BS, 100\% ML BS, 1.00 BI PP; Figs. 2, 3; this clade is also resolved and well supported in the separate trees; Fig. 1). The subgenus Morus clade consists of a well-supported clade of all Asian Morus species (100\% MP BS, 100\% ML BS, PP 1.0; see also Fig. 1) and a clade of North American taxa (including M. celtidifolia, which ranges into Central America; 91\% MP BS, 93\% ML BS, 0.95 BI PP; see also Fig. 1). Relationships among the Asian Morus species are unresolved (Fig. 2) except for a weakly supported sister relationship between M. cathayana and M. macroura (64\% MP BS, 65\% ML BS, 0.95 BI PP). Within the North American clade, M. microphylla and $M$. celtidifolia are strongly supported as sister, with M. rubra sister to the M. microphylla-M. celtidifolia clade. Thus the native North American M. rubra and the Asian M. alba, which are known to hybridize in nature (e.g. Burgess et al. 2005) fall into distinct clades within subgenus Morus.

2) Morus is non-monophyletic as currently circumscribed (a result also supported by separate trees; Fig. 1). A sister relationship between sampled members of Trophis and subgenus Morus is well-supported (Figs. 2 and 3; 91\% MP BS, $100 \%$ ML BS, 0.79 BI PP). A clade of M. mesozygia (Leroy's Subg. Afromorus) and M. insignis (Leroy's subg. Gomphomorus) is weakly supported (Figs. 2 and 3; 66\% MP BS, 67\% ML BS, $0.91 \mathrm{BI} P \mathrm{PP})$, with this clade resolved as sister to the subgenus Morus-Trophis s. s. clade. Samples of Sorocea form a wellsupported clade (Figs. 2 and 3; 100\% MP BS, 100\% ML BS, 1.00 BI PP), and this clade and the sample of Bagassa fall outside of Morus (Fig. 2). However, short branch lengths indicate poor support for relationships among genera based on the ITS and trnL-trnF data (Fig. 3).

TABLE 1. Statistics from parsimony analyses of different data sets including consistency index (CI) and retention index (RI). The CI values listed are excluding uninformative characters. Number of taxa included in analyses were 25, 21 and 20 for for ITS, trnL-trnF and combined data set, respectively.

\begin{tabular}{|c|c|c|c|c|}
\hline Gap handling & Description & ITS (ITS1, 5.8S, ITS2) data set & $\operatorname{trn} L-\operatorname{trn} F$ ( $\operatorname{trn} L$ intron, IGS) data set & Combined data set \\
\hline \multirow[t]{5}{*}{ Gap as missing } & Parsimony informative characters & $144(84,8,49)$ & $15(9,6)$ & 138 \\
\hline & Number of most parsimonious trees & 142 & 186 & 80 \\
\hline & Tree lengths & 469 & 113 & 443 \\
\hline & $\mathrm{CI}$ & 0.6130 & 0.5932 & 0.6325 \\
\hline & RI & 0.8027 & 0.8437 & 0.8267 \\
\hline \multirow[t]{5}{*}{ Gap as fifth character state } & Parsimony informative characters & $202(132,8,62)$ & $27(17,10)$ & 197 \\
\hline & Number of most parsimonious trees & 8 & 18 & 7 \\
\hline & Tree lengths & 692 & 146 & 610 \\
\hline & $\mathrm{CI}$ & 0.6760 & 0.6591 & 0.7003 \\
\hline & RI & 0.8307 & 0.8598 & 0.8452 \\
\hline
\end{tabular}



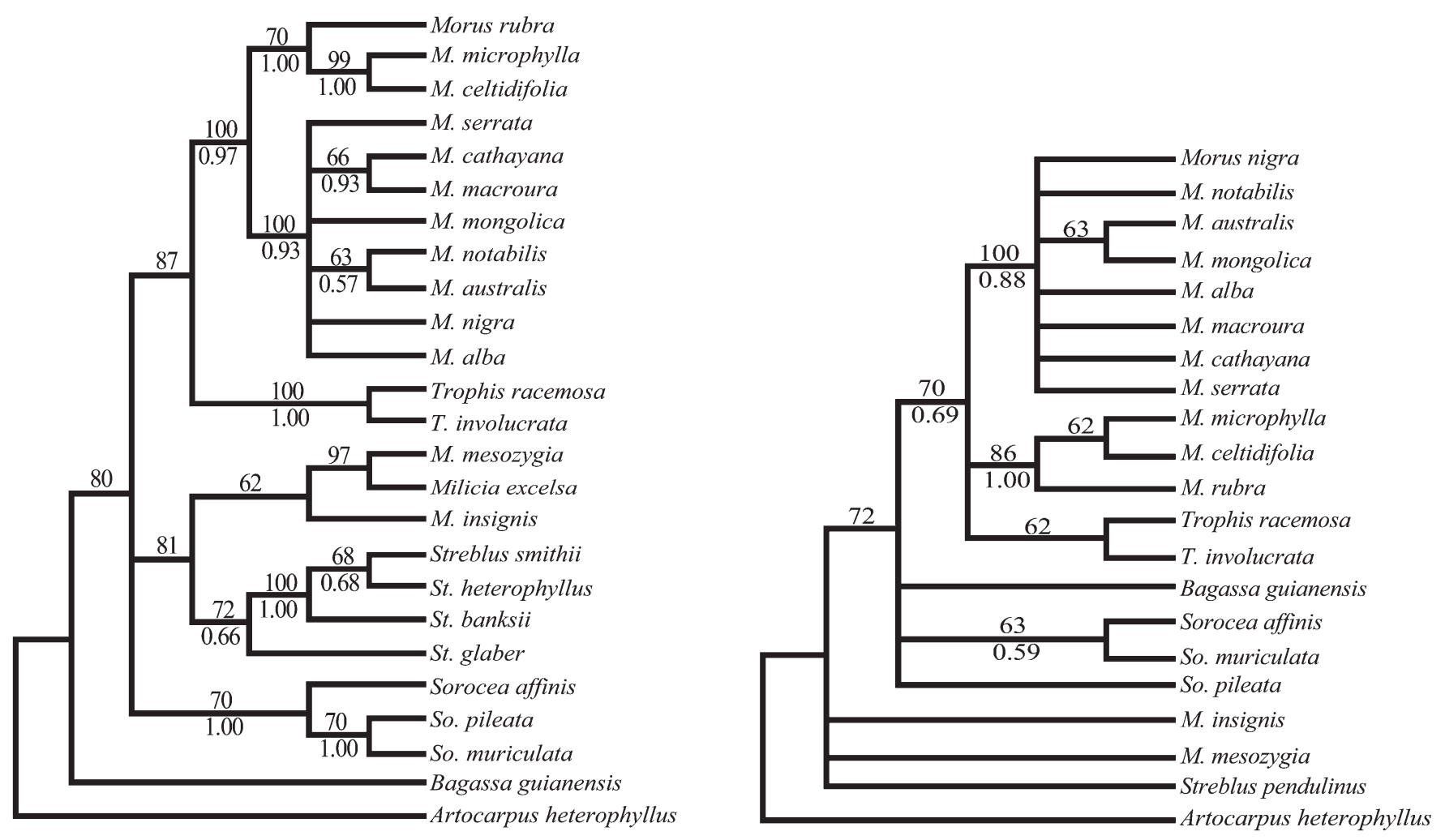

FIG. 1. Maximum Parsimony strict consensus trees for ITS (left; 8 trees, $\mathrm{CI}=0.6760$ and RI $=0.8307$ ) and trnL-trnF (right; 18 trees, $\mathrm{CI}=0.6591$ and $\mathrm{RI}=$ 0.8598 ) resulting from analyses with gaps coded as a fifth character state. The numbers above the branches are MP bootstrap values based on 20,000 replicates and numbers below the branches are BI posterior probabilities.

Separate analyses of ITS and trnL-trnF, each with slightly different sampling outside of Morus, do not resolve M. mesozygia and $M$. insignis with the subgenus Morus-Trophis s. s. clade (Fig. 1). In the ITS MP strict consensus, M. mesozygia and Milicia excelsa are sister (with strong MP BS support, 97\%, but without PP support), and that clade together with $M$. insignis form a poorly supported clade (MP BS 62\%) which is in turn sister to a Streblus clade (MP BS 81\%; Fig. 1). Relationships of the subgenus Morus-Trophis s. s. clade, the M. mesozygiaMilicia excelsa-M. insignis-Streblus clade and a clade of Sorocea are unresolved, while Bagassa guianensis falls as sister to that entire clade (MP BS 80\%; Fig. 1). There is less sampling of Tribe Moreae for $t r n L-t r n F$, and $t r n L-t r n F$ is generally less resolved and supported (Fig. 1). The subgenus Morus-Trophis s. s. clade forms a polytomy with Bagassa guianensis, a weakly supported clade of M. mesozygia and M. insignis (MP BS 63\%, PP 0.59), and Sorocea affinis; and the remaining samples, S. muriculata, S. pileata, and Streblus pendulinus form unresolved relationships in the interior of the tree (Fig. 1).

\section{Discussion}

Phylogenetic Relationships of Morus-Most of Morus forms a well-supported monophyletic group which corresponds to Morus subgenus Morus sensu Leroy (1949). Within this core Morus group, all Asian species (including the type of Morus, M. nigra) form a clade, and the native North American taxa (including $M$. celtidifolia, which ranges into Central America) form a clade. Given our sampling of Tribe Moreae, Trophis s. s. (T. racemosa is synonymized with T. americana L., which is the type of Trophis [Berg 2001]) is sister to Morus subgenus Morus (a close relationship between Morus and some members of Trophis has previously been documented by Datwyler and Weiblen [2004] and Zerega et al. [2005]). The African M. mesozygia (Leroy's Subg. Afromorus) and the Neotropical M. insignis (Leroy's Subg. Gomphomorus) are more distantly related to subgenus Morus, rendering Morus non-monophyletic.

This study represents the most comprehensive phylogenetic study of Morus to date. The thirteen species of Morus included in the phylogeny are morphologically distinct from one another and are representative of the diversity of the genus. Indeed, sampling of Morus herein may be considered comprehensive (see Berg 2001, 2005a; Nepal 2008), although some workers have split the genus more extensively (particularly in Asia, Zhekun and Gilbert 2003; see also Greene's treatment of variation in the southwestern U. S. A. [synonymized within M. microphylla], Greene 1910) and, as noted by Berg (2005a), a modern worldwide monograph is lacking. The ITS and trnL-trnF regions do not provide sufficient variation to resolve relationships at the "tips" of the tree within Morus. Zhao et al. (2005) used sequences of ITS and the trnL intron to infer relationships based on genetic distance among some Asian taxa (with additional population sampling relative to the present study), but parsimony analysis of their sequences (obtained from GenBank; data not shown) yields unresolved relationships. Future studies employing more variable DNA regions with extensive sampling (including the breadth of diversity considered here) will be valuable.

Subgenus Morus, Asian Clade-Relationships within the Asian clade, which harbors the most taxonomic diversity of the genus, are largely unresolved. Of the eight species, three 


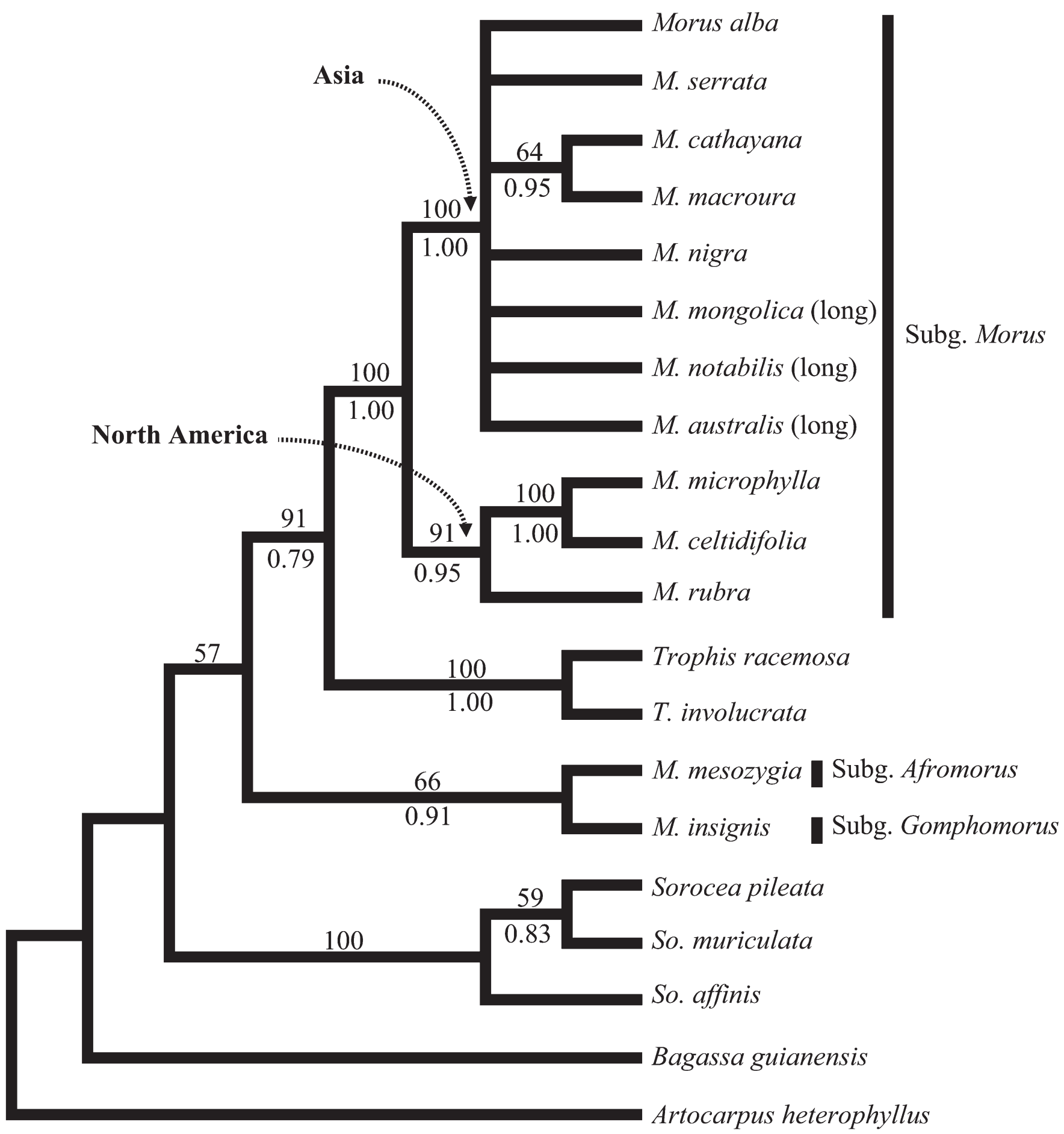

FIG. 2. Strict consensus of seven most parsimonious trees $(\mathrm{CI}=0.7003$ and $\mathrm{RI}=0.8452)$ based on the combined ITS/trnL-trnF data set with gaps coded as a fifth character state. The numbers above the branches are MP bootstrap values based on 20,000 replicates and numbers below the branches are BI posterior probabilities. Bars to the right indicate the subgeneric groupings of Leroy (1949). Within the subgenus Morus clade, arrows indicate the clade of Asian species and the clade of North American species. Morus species exhibiting long styles (sensu Koidzumi; > $1 \mathrm{~mm}$ ) are designated "long" in parentheses following the taxon name.

are characterized by a long style (> $1 \mathrm{~mm}$; $M$. australis, $M$. mongolica, and $M$. notabilis), and the remaining five have a short style (<0.5 mm; M. alba, M. serrata, M. cathayana, M. macroura, and M. nigra; as do other Morus species outside of the Asian clade). The phylogeny is consistent with a hypothesized single origin of the long style (Koidzumi's Sect. Dolichostylae; Koidzumi, 1917; Zhekun and Gilbert 2003): relationships are unresolved in the combined tree but $M$. australis groups with and $M$. notabilis in the ITS tree and with M. mongolica in the trnL-trnF tree, though with weak support in each case. Morus mongolica differs from the other long-styled species in having a long pointed apiculum on the leaves; and $M$. australis and $M$. notabilis are differentiated from each other in leaf shape, leaf apex, and infructescence 


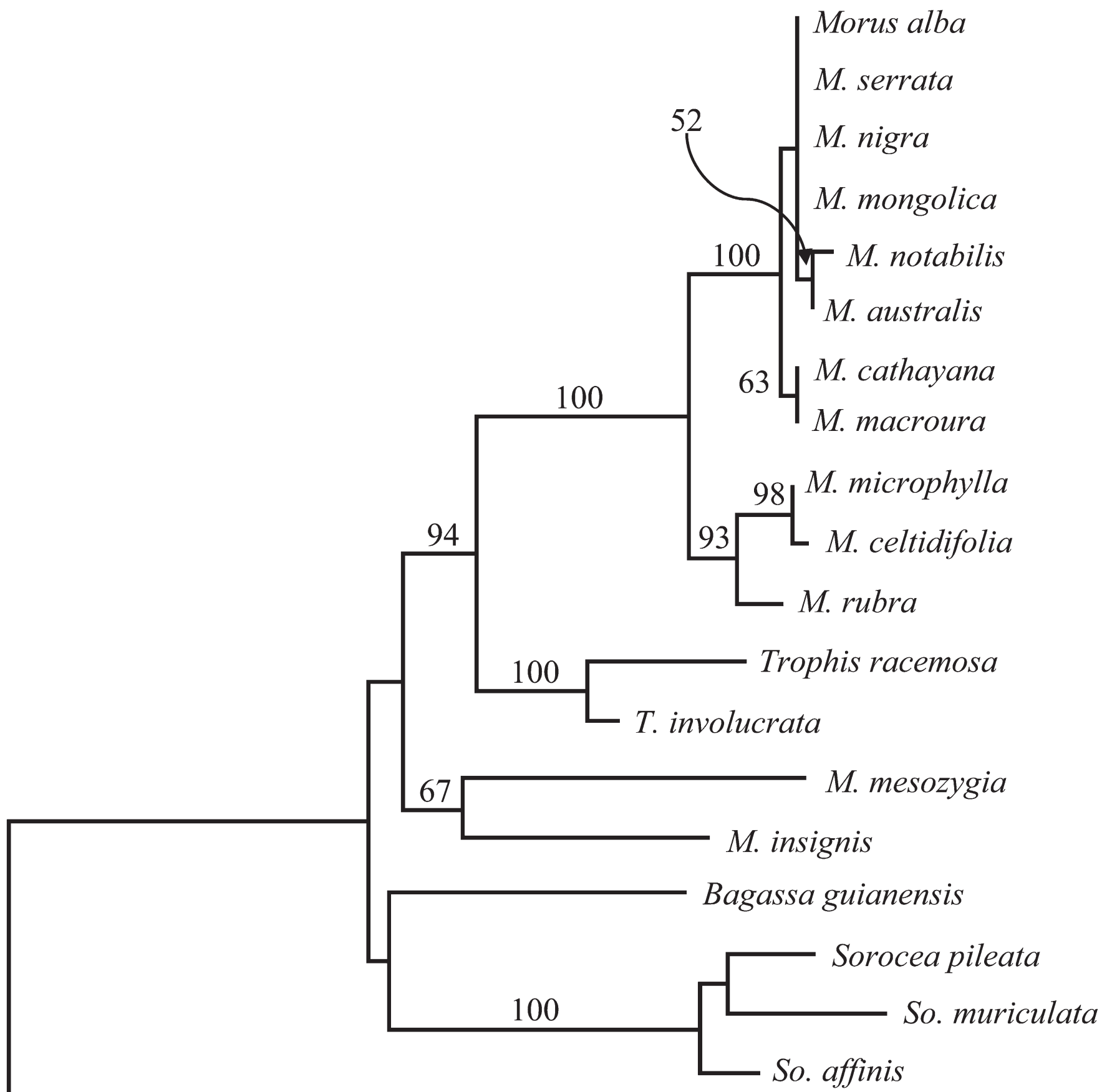

\section{Artocarpus heterophyllus}

\section{- 0.005 substitutions/site}

FIG. 3. Maximum Likelihood phylogram (-Ln likelihood $=4,700.73975$, the most likely tree) based on the combined data set using a K81uf $+\mathrm{G}$ evolutionary model. Numbers above the branches are ML bootstrap values based on 1,000 replicates.

length characters. Morus cathyana and M. macroura, which are grouped with weak support (Fig. 2) share a long catkin length $(>2 \mathrm{~cm})$ and larger axillary buds $(0.2-1 \mathrm{~cm} \times 0.5 \mathrm{~cm})$ relative to other Asian species (see Nepal 2008). The known variation in ploidy levels within Morus (from $2 x$ to $22 x, x=14$; Janaki-Ammal 1948; Chen et al. 1993; Azizan and Sonboli 2001) occurs among the Asian species and thus could not be assessed in light of the current phylogeny. Similarly, classification based on leaf cystolith cells (Hotta 1954) could not be fully evaluated. Interestingly, all of the taxa in the Asian clade correspond to only two species sensu Bureau (1873), who would have recognized $M$. nigra and $M$. alba, with all other taxa recognized herein as varieties of the latter.

Several population genetic studies have been conducted on Asian species of Morus, investigating genetic variation between genotypes and varieties, and even exploring interspecific relationships (e.g. Sharma et al. 2000; Bhattacharya and Ranade 2001; Awasthi et al. 2004; Vijayan et al. 2006; 
Zhao et al. 2007). Of these, the only study to sample outside of subgenus Morus was that of Sharma et al. (2000; using AFLPs). They included one sample of the African M. mesozygia (discussed below; M. insignis was not included), and, interestingly, it grouped with a large cluster of highly similar samples including M. microphylla, M. celtidifolia, and M. nigriformis $(=M$. alba $)$, while samples they listed as $M$. laevigata $(=M$. macroura), M. tiliaefolia (= M. macroura), and M. boninensis (= M. australis) were more genetically distant. It is important to note that phenograms depicting genetic distance may not correspond to phylogenetic relationships; furthermore, ascertaining evolutionary relationships was not an aim of most of these studies, rather, the focus was generally on genetic similarity, often for breeding purposes.

Subgenus Morus, North American Clade-Our findings support a single origin of native New World species (M. rubra, M. microphylla, and M. celtidifolia), sister to the Asian clade within subgenus Morus. The southwestern species M. microphylla (North America) and M. celtifidolia (Central America) are sister species, with that clade sister to the widespread eastern North American M. rubra. Intriguing ecological and population genetic work in North America demonstrates that the native $M$. rubra hybridizes naturally with the introduced $M$. alba in some areas; moreover the introduced species may represent a threat to the increasingly uncommon native species through genetic swamping (e.g. Vila et al. 2000; Burgess et al. 2005, 2008). Despite their ability to hybridize, M. rubra and M. alba are not sister species.

The African M. mesozygia and Neotropical M. insignisThese distinctive species formed a clade separate from all other Morus (and rendering the genus non-monophyletic; discussed below). Morus mesozygia (Subg. Afromorus) occurs in eastern tropical Africa, and exhibits distinctive leaf and syncarp morphology (autapomorphies): the leaves are ovate to orbicular with tri-nerved primary veins, less prominent secondary veins (from the mid-rib), and are scalariform except for two to three pairs of lateral veins towards the leaf apex; penduncles are longer than the inflorescence; and fruits are fewer than in other Morus species and are less compact (see Nepal 2008). The Neotropical M. insignis (Subg. Gomphomorus) likewise exhibits unique morphology: the leaves are elliptic with minutely serrate to subentire margins; axillary buds are small $(0.2-0.5 \mathrm{~cm} \times 0.2 \mathrm{~cm})$; and petioles are long (0.5-3 cm; Berg 2001). Similarities between M. insignis and $M$. macroura (tree height and long syncarps, in addition to occurring in tropical montane habitats) are presumably due to parallel evolution. Further work (including thorough investigation of Trophis) will be necessary to assess potential morphological synapomorphies corresponding to molecular phylogenetic findings.

Relationships of Morus within the Tribe Moreae-Our phylogenetic findings indicate that Morus, as currently circumscribed, is non-monophyletic. The clade of two species of the genus Trophis (of ca. 10 species total; Rohwer 1993) is sister in both the ITS and combined trees to the subgenus Morus clade (in the trnL-trnF tree, relationships among the Trophis clade and the Asian and North American clades of Subg. Morus are unresolved). In both of the separate trees and the combined tree, the remaining Morus taxa (M. mesozygia and M. insignis) fall outside of a subgenus Morus-Trophis s. s. clade. The close relationship of Morus and some members of Trophis has been found in other studies (Datwyler and Weiblen 2004; Zerega et al. 2005; see also
Clement and Weiblen 2009); and these same studies have demonstrated, furthermore, that Trophis (as well as Streblus) is non-monophyletic, with some taxa more closely related to members of Tribe Dorstenieae. Morus and Trophis species included in the present study share a red or orange color of the inflorescence rachis, undifferentiated perianth of the pistillate flower into an upper and lower part, and inflexed stamens (Berg 2001). The Trophis species reportedly differ, however, in having persistent terminal buds and valvate perianth as opposed to caducous terminal buds and imbricate perianth in all Morus species (Berg 2001). Weiblen and co-workers have suggested further work on Trophis (Datwyler and Weiblen 2004; Zerega et al. 2005; Clement and Weiblen 2009); it is now clear that this work must take into consideration relationships of the genus Morus as well.

Outside of the subgenus Morus-Trophis s. s. clade, confident inference of relationships is not yet possible. In the ITS phylogeny, M. mesozygia and $M$. insignis are paraphyletic to the single sample of Milicia, and that clade in turn is sister to a monophyletic Streblus. In considering the combined tree, it is important to note that Milicia and Streblus were not included because $t r n L-t r n F$ data were unavailable. Therein, M. mesozygia and $M$. insignis resolved as a clade sister to subgenus Morus-Trophis s. s., with a monophyletic Sorocea and the single sample of Bagasssa each subsequently basal. However, the interior region of the phylogeny is poorly supported and exhibits short branch lengths, and our study thus adds to others that have noted poor phylogenetic resolution and taxonomic challenges within this part of the Tribe Moreae phylogeny (Datwyler and Weiblen 2004; Zerega et al. 2005; Clement and Weiblen 2009).

Our finding of a non-monophyletic Morus is novel, and recovery of particular clades with geographic integrity (the Asian and North American clades of Subg. Morus) as well as the positions of African M. mesozygia and Neotropical $M$. insignis lay important groundwork for further systematic study of Morus. This study also highlights the importance of ongoing work to resolve relationships and circumscribe natural genera within Tribe Moreae.

ACKNOWLEDGments. Support for this project came from an American Society of Plant Taxonomists (ASPT) Graduate Student Research Grant (2007), and a Kansas State University Rotary Club International Graduate Student Research Award (2006). The support of the Kansas State University Division of Biology and the Konza Prairie Long Term Ecological Research (LTER) program is also gratefully acknowledged. Extension of this project to the tribe level, data analyses, and manuscript development/ revision were carried out at South Dakota State University where MPN is currently employed. Missouri Botanical Garden Herbarium (MO) and Gray Herbarium (GH) granted permission to sample material from herbarium specimens for molecular work. Drs. George Weiblen and Wendy Clement (University of Minnesota) graciously provided DNA samples of Trophis and Sorocea, as well as valuable advice on sampling; and Mr. T. N. Bhattarai (Nepal) and Sharada Krishnan (Denver Botanical Garden) graciously provided samples of $M$. serrata and $M$. nigra, respectively. Three anonymous reviewers provided valuable comments that greatly improved the manuscript. This work is based upon the dissertation research of MPN, and he gratefully acknowledges the input of his committee members, Drs. Karen Garrett, David Hartnett, Mark Mayfield, and Mark Ungerer. We are also grateful to Shannon Fehlberg and Molly Bernstein for technical assistance and useful discussion. This is contribution number 11-336-J of the Kansas Agricultural Experiment Station.

\section{Literature Cited}

Aggarwal, R. K., P. S. Hendre, A. Sarkar, L. I. Singh, and D. Udaykumar. 2004. Isolation and characterization of six novel microsatellite 
markers for mulberry (Morus indica). Molecular Ecology Notes 4: 477-479.

Awasthi, A. K., S. Kanginakudru, G. M. Nagaraja, J. Nagaraju, G. V. Naik, and K. Thangavelu. 2004. Genetic diversity and relationships in mulberry (genus Morus) as revealed by RAPD and ISSR marker assays. BMC Genetics 5: 1-9.

Azizan, D. and A. Sonboli. 2001. Chromosome counts for five species of Moraceae from Iran. Iranian Journal of Botany 9: 103-106.

Berg, C. C. 2001. Moreae, Artocarpeae, and Dorstenia (Moraceae) with introductions to the family and Ficus and with additions and corrections to Flora Neotropica Monograph 7. New York: New York Botanical Garden Press.

Berg, C. C. 2005a. Moraceae diversity in a global perspective. Proceedings of an international symposium on plant diversity and complexity patterns: local, regional, and global dimensions at Royal Danish Academy of Science, Copenhagen, Denmark. Biologiske Skrifter 55: $423-440$.

Berg, C. C. 2005b. Flora Malesiana precursor for the treatment of Moraceae 8: Other genera than Ficus. Blumea 50: 535-550.

Bhattacharya, E. and S. A. Ranade. 2001. Molecular distinction among varieties of mulberry using RAPD and DAMD profiles. BMC Plant Biology 1: 1-8.

Bureau, E. 1873. Moraceae. Pp. 211-288 in Prodromus systematis naturalis regni vegetabilis. Volume 17, ed. A. P. DeCandolle. Paris: Tuettel and Wurtz.

Burgess, K. S., L. Deverno, B. C. Husband, and M. Morgan. 2005. Asymmetrical introgression between two Morus species (M. alba, M. rubra) that differ in abundance. Molecular Ecology 14: 3471-3483.

Burgess, K. S., M. Morgan, and B. C. Husband. 2008. Inter-specific seed discounting and the fertility cost of hybridization in red mulberry (Morus rubra L.). The New Phytologist 177: 276-284.

Cao, Z. Y. 1991. New taxa of Morus (Moraceae) from China. Acta Phytotaxonomica Sinica 29: 264-267.

Chang, S. S. 1984. New taxa of Moraceae from China and Vietnam. Acta Phytotaxonomica Sinica 22: 64-76.

Chen, R. Y., W. Q. Song, G. L. Liang, S. H. Lin, X. L. Li, and Z. P. An. 1993. Chromosome atlas of Chinese fruit trees and their close wild relatives. Chromosome atlas of Chinese principal economic plants. Volume 1. Beijing: International Academic Publishers.

Clement, W. L. and G. D. Weiblen. 2009. Morphological evolution in the mulberry family (Moraceae). Systematic Botany 34: 530-552.

Datwyler, S. L. and G. D. Weiblen. 2004. On the origin of the fig: phylogenetic relationships of Moraceae from $n d h F$ sequences. American Journal of Botany 91: 767-777.

Downie, S. R. and D. S. Katz-Downie. 1996. A molecular phylogeny of Apiaceae Subfamily Apioideae: evidence from nuclear ribosomal DNA internal transcribed spacer sequences. American Journal of Botany 83: 234-251.

Doyle, J. J. and J. L. Doyle. 1987. A rapid DNA isolation procedure for small quantities of fresh leaf tissue. Phytochemical Bulletin 19: 11-15.

Farris, J. S., C. Bult, M. Källersjö, and A. G. Kluge. 1994. Testing significance of incongruence. Cladistics 10: 315-319.

Felsenstein, J. 1985. Confidence limits on phylogenies: an approach using the bootstrap. Evolution 39: 783-791.

Gray, E. and R. E. Gray. 1987. Leaf lobation patterns in mulberry. Castanea 52: $216-224$.

Greene, E. L. 1910. Some southwestern mulberries. Pp. 112-121 in Leaflets of botanical observation and criticism vol. 2, ed. E. L. Green. Washington D. C.: Smithsonian Institution Press.

Holmgren, P. K., L. C. Bartnett, and N. H. Holmgren (eds.). 1990. Index Herbariorum. part 1: the herbaria of the world. 8th edition. Bronx: New York Botanical Garden.

Hotta, T. 1954. Fundamentals of Morus plants classification (in Japanese). Kinugasa Sanpo 390: 13-21.

Huelsenbeck, J. P. and F. Ronquist. 2001. MRBAYES: Bayesian inference of phylogeny. Bioinformatics 17: 754-755.

Janaki-Ammal, E. K. 1948. The origin of black mulberry. Journal of the Royal Horticultural Society 73: 117-120.

Katsumata, F. 1971. Shape of idioblasts in mulberry leaves with special reference to the classification of mulberry trees. Journal of Sericultural Science of Japan 40: 313-322.

Koidzumi, G. 1917. Taxonomy and phytogeography of the genus Morus. Bulletin of Sericultural Experimental Station 3: 1-62. (Tokyo).

Leroy, J. F. 1949. Les Muriers sauvages et cultives. La sericiculture sous les tropiques. Revue Internationale de Botanique aaplique'e et d'agriculture Tropicale 29: 481-496.
Linnaeus, C. 1753. Morus. P. 968 in Species plantarum vol. 2. Stockholm: Impensis Laurentii Salvii.

Loockerman, D. J. and R. K. Jansen. 1996. The use of herbarium material for DNA studies. Pp. 205-220 in Sampling the green world, eds. T. F. Stuessy and S. J. Sohmer. New York: Columbia University Press.

Nepal, M. P. 2008. Systematics and reproductive biology of the genus Morus L. (Moraceae). Ph. D. dissertation, Manhattan: Kansas State University.

Posada, D. and K. Crandall. 1998. MODELTEST: testing the model of DNA substitution. Bioinformatics 14: 817-818.

Posada, D. and T. R. Buckley. 2004. Model selection and model averaging in phylogenetics: advantages of the AIC and Bayesian approaches over likelihood ratio tests. Systematic Biology 53: 793-808.

Rambaut, A. 2002. Se-Al v2.0a11 Carbon. Oxford, U. K.: University of Oxford.

Rao, C. K. and C. E. Jarvis. 1986. Lectotypification, taxonomy and nomenclature of Morus alba, M. tatarica and M. indica (Moraceae). Taxon 35: 705-708.

Rohwer, J. G. 1993. Moraceae. Pp 438-453 in The families and genera of vascular plants. Volume 2. Flowering plants. Dicotyledons. Magnoliid, Hamamelid and Caryophyllid families, eds. K. Kubitzki, J. G. Rohwer, and V. Bittrich. Berlin: Springer-Verlag.

Rønsted, N., G. D. Weiblen, W. Clement, N. Zerega, and V. Savolainen. 2008. Reconstructing the phylogeny of figs (Ficus, Moraceae) to unravel the origin of fig-wasp mutualisms. Symbiosis 45: 45-56.

Sanjappa, M. 1989. Geographical distribution and exploration of the genus Morus L. (Moraceae). Pp. 4-7 in Genetic resources of mulberry and utilization, eds. K. Sengupta and S. B. Dandin. Mysore, India: CSRTI.

Sharma, A., H. Machii, and R. Sharma. 2000. Assessment of genetic diversity in a Morus germplasm collection using fluorescence-based AFLP markers. Theoretical and Applied Genetics 101: 1049-1055.

Shaw, J., J. T. Beck, S. B. Farmer, E. B. Lickey, W. Liu, J. Miller, E. E. Schilling, K. C. Siripun, R. L. Small, and C. T. Winder. 2005. The tortoise and the hare II: relative utility of 21 non-coding chloroplast DNA sequences for phylogenetic analysis. American Journal of Botany 92: $142-166$.

Stapanian, M. A. 1982. A model for fruiting display: seed dispersal by birds for mulberry trees. Ecology 63: 1432-1443.

Swofford, D. 2002. PAUP*. Phylogenetic analysis using parsimony (* and other methods), version 4.0b10. Sunderland: Sinauer Associates.

Sytsma, K. J., M. W. Chase, E. Conti, J. C. Hall, J. Morawetz, M. Nepokroeff, J. C. Pires, and M. Zjhra. 2002. Urticalean rosids: circumscription, rosid ancestry, and phylogenetics based on $r b c L$, trnL-trnF, and $n d h F$ sequences. American Journal of Botany 89: 1531-1546.

Taberlet, P., J. Bouvet, L. Gielly, and G. Pautou. 1991. Universal primers for amplification of three non-coding regions of chloroplast DNA. Plant Molecular Biology 17: 1105-1109.

Tani, N., T. Kawahara, and H. Yoshimaru. 2005. Development and diversity of microsatellite markers for endangered species Morusboninensis Koidz. to establish conservation program. Molecular Ecology Notes 5: 398-400.

Tojyo, I. 1985. Research of polyploidy and its application in Morus. Japan Agricultural Research Quarterly 18: 222-228.

Vijayan, K., A. K. Awasthi, P. K. Kar, B. Saratchandra, P. P. Srivastava, K. Thangavelu, and A. Tikader. 2004. Molecular evaluation of genetic variability in wild populations of mulberry (Morus serrata Roxb.). Plant Breeding 123: 568-572.

Vijayan, K., A. K. Awasthi, C. V. Nair, B. Sreenivasa, P. P. Srivatsava, A. Tikader, and S. R. Urs. 2006. Molecular characterization and identification of markers associated with yield traits in mulberry using ISSR markers. Plant Breeding 125: 298-301.

Vila, M., E. Weber, and C. M. D'Antonio. 2000. Conservation implications of invasion by plant hybridization. Biological Invasions 2: 207-217.

Watanabe, T. 1958. Substances in mulberry leaves which attract silkworm larvae (Bombyx mori L.). Nature 182: 325-326.

White, T. J., T. Bruns, S. Lee, and J. Taylor. 1990. Amplification and direct sequencing of fungal ribosomal RNA genes for phylogenetics. Pp. 315-322 in PCR protocols: a guide to methods and applications, eds. M. Innis, D. Gelfand, J. Snisky, and T. J. White. San Diego: Academic Press.

Wu, C. Y. and S. S. Chang. 1989. Taxa nova nonnulla Moracearum sinensium. Acta Botanica Yunanica 11: 24-34.

Zerega, N. J. C., W. L. Clement, S. L. Datwyler, and G. D. Weiblen. 2005. Biogeography and divergence times in the mulberry family (Moraceae). Molecular Phylogenetics and Evolution 37: 402-416. 
Zerega, N. J. C., M. N. Nur Supardi, and T. J. Motley. 2010. Phylogeny and recircumscription of Artocarpeae (Moraceae) with a focus on Artocarpus. Systematic Botany 35: 766-782.

Zhao, W., Y. Huang, S. Jia, X. Miao, and Y. Pan. 2005. Isolation and characterization of microsatellite loci from the mulberry, Morus L. Plant Science 168: 519-525.

Zhao, W., Y. Huang, S. Jia, X. Miao, Y. Pan, and Z. Zhang. 2007. Phylogeny of the genus Morus (Urticales: Moraceae) inferred from ITS and trnL- trnF sequences. African Journal of Biotechnology 4: 563-569.

Zhekun, Z. and M. G. Gilbert. 2003. Moraceae. Pp 21-73 in Flora of China vol. 5, eds. Flora of China Editorial Committee. St. Louis: Missouri Botanical Garden Press.

APPENDIx 1. Morus species sampled, with information on general morphology (see Nepal 2008), native range, voucher information and collection location (abbreviations for herbaria follow Holmgren et al. 1990), and GenBank accession numbers for ITS and trnL-trnF.

Morus alba L., Leaf blade abaxially sparse pubescent along the veins, adaxially glabrous, margin irregularly dentate, apex usually obtuse, style absent or indistinct, infructescence globose up to $1.5 \mathrm{~cm}$, Asia: South and Central China, Nepal 396, Kansas, United States (KSC) (introduced), HM747164, HM747180; M. australis Poir., Leaf margin without setae (apicula), leaf apex often acuminate to subcaudate, style long (>1 mm), infructescence 0.5-2 cm, Asia: China, India, Japan, Korea, Nepal, Murata 71055, Kyushu, Japan (GH), HM747166, HM747182; M. cathayana Hemsl., Leaf apex acute to acuminate, cordate base, style short $(<0.5 \mathrm{~mm})$ or absent, infructescence 2-5 cm, Asia: China, Japan, Korea, Xia and Ren 1999-1025344, Yunnan, China (MO), HM747167, HM747183; M. celtidifolia Kunth, Leaf abaxially harshly pubescent to scabrous, base usually unequal to cordate, adaxially slightly scabrous, style short, infructescence 1-2 cm, Central America: Mexico to Honduras, Carranza 1560, Mexico (MO), HM747168, HM747184; M. insignis Bureau, Axillary bud smallest in the genus $(0.2-0.5 \mathrm{~cm} \times 0.2 \mathrm{~cm})$, petiole $1-2.5 \mathrm{~cm}$, leaf lanceolate to elliptic, margin minutely serrate to subentire, peduncle $<0.5$, style short, infructescence $5-16 \mathrm{~cm}$ or longer, Central and South America: From Northern Argentina to southern Mexico, Homeier 615, Zamora-Chinchipe, Ecuador (MO), HM747169, HM747185; M. macroura Miq., Petiole 2.5$6 \mathrm{~cm}$, leaf blade ovate to broadly ovate, margin sub-entire to minutely serrate, peduncle $>0.5 \mathrm{~cm}$, style short, infructescence $5-16 \mathrm{~cm}$ or longer, Asia: Burma, China, India, Indonesia, Thailand, Nepal, Maxwell 90-272, Chiang Dao, Thailand (MO), HM747170, HM747186; M. mesozygia Stapf., Leaf ovate to orbicular, secondary venation scalariform except for two to three pairs toward the leaf apex, peduncle longer than inflorescence, style short, infructescence 0.5-2.5 cm, Africa: Eastern Continental Africa, Maishanu, ATBP 639, Uganda (MO), HM747171, HM747187; M. microphylla Buckley, Shrubs to trees up to $5 \mathrm{~m}$, ovate to ovate-lanceolate, adaxially harshly scabrous, style short, infructescence small $(\mathrm{ca} .0 .5 \mathrm{~cm}$; excluding the peduncle), North America: United States and Mexico, Merello and Schmid 1889 Arizona, United States (MO), HM747172, HM747188; M. mongolica (Bur.) C. K. Schneid., Leaf margin with acute dentation characterized with a short to long setae (apicula), style long (>1 mm), stigma uniquely swollen, infructescence up to $2 \mathrm{~cm}$, Asia: China, Japan, Korea, Taiwan, Liu and Zheng 202, Gansu, China (MO), HM747173, HM747189; M. nigra L., Leaf broadly ovate with cordate base, abaxially sparsely pubescent along the veins, glabrous adaxially or slightly scabrous, leaf margin with wider teeth, style short, infructescence oblong 1.5-2 cm, Asia: Western Iran, Krishnan 813, Colorado, United States (KHD) (cultivated), HM747174, HM747190; M. notabilis C. K. Schneid., Leaf abaxially densely pubescent, glabrous adaxially, leaf margin with wider teeth, slightly drooping branches, style long, infructescence cylindric, 2.5-4 cm, Asia: South and Central China, Heng 11734, Yunnan, China (GH), HM747175, HM747191; M. rubra L., Leave ovate with often cordate base, surface abaxially densely pubescent, adaxially often scabrous, stem with horizontally spreading (slightly drooping) branches, style short, infructescence cylindric, up to $2 \mathrm{~cm}$, North America: Eastern United States to southeastern Canada, Nepal 701, Kansas, United States (KSC), HM747165, HM747181; M. serrata Roxb., Leaf margin with evenly spaced triangular teeth, semi persistent bud scales and stipules, style short, stigma densely pubescent, infructescence less than $2 \mathrm{~cm}$, Asia: China, India, Nepal, Bhattarai 1, Ilam, Nepal (KSC), HM747176, HM747192.

ApPENDIx 2. Information for additional ingroup samples of Tribe Moreae sensu Clement and Weiblen (2009), and outgroup taxon Artocarpus heterophylla, including voucher information for new sequences reported in the present study, and GenBank accession numbers for ITS and trnL-trnF. Taxon names for sequences obtained from GenBank follow GenBank listings (differences in determination listings in publication are noted in brackets).

Bagassa guianensis Aubl., no voucher, FJ917001, FJ917066; Milicia excelsa (Welw.) C. C. Berg, no voucher, MEU93585,-; Sorocea affinis Hemsl., Weiblen 1437, Costa Rica (MIN), HM747179,HM747195; Sorocea muriculata Miq. [S. steinbachii C. C. Berg; Zerega et al. 2010], no voucher, FJ916998, FJ917063; Sorocea pileata Burger [S. briquetii J. F. Macbr.; Zerega et al. 2010], no voucher, FJ916999, FJ917064; Streblus banksii (Cheesem.) Webb, no voucher, EF635452,-; Streblus glaber (Merr.) Corner, no voucher, DQ499105,-; Streblus heterophyllus (Blume) Corner, no voucher, DQ499106,-; Streblus smithii (Cheesem.) Corner, no voucher, EF635447,-; Streblus pendulinus (Endl.) F. Muell., no voucher,-, AF501609; Trophis involucrata W. Burger, Weiblen 1405, Costa Rica (MIN), HM747177, HM74719; T. racemosa (L.) Urban, Weiblen 1400, Costa Rica (MIN), HM747178, HM747194;

Outgroup: Artocarpus heterophyllus Lam., no voucher, FJ917052, FJ917113. 